\title{
Empirical estimation of pollution load and contamination levels of phthalate esters in agricultural soils from plastic film mulching in China
}

\author{
Yongshan Chen $\cdot$ Chunfa Wu $\cdot$ Haibo Zhang • \\ Qiaoying Lin · Youwei Hong • Yongming Luo
}

Received: 8 December 2011/Accepted: 7 November 2012/Published online: 1 December 2012

(c) Springer-Verlag Berlin Heidelberg 2012

\begin{abstract}
Pollution load and contamination levels of phthalate esters (PAEs) in agricultural soils throughout China were studied in this work. The usage amount and residual rates of plastic film were the main factors explaining the variation among regions and leading to higher pollution load and contamination levels in agricultural big provinces. However, higher pollution loads and contamination levels frequently occurred under non-recycling than recycling scenarios during calculation. Extremely high loads (more than $10 \mathrm{~kg} / \mathrm{ha} /$ year) of PAEs were estimated in five areas including Beijing city, Tibet, Liaoning Province, Jilin Province and Fujian Province and the high contamination levels in agricultural soil were presented in these places with more than $4.0 \mathrm{mg} / \mathrm{kg}$ under nonrecycling scenarios. The predicted concentrations of PAEs in soils exceed the target value for soils from Netherlands ( $\Sigma$ PAEs $=0.1 \mathrm{mg} / \mathrm{kg}$ ), indicating very high contamination of most Chinese agricultural soils. Significant differences in estimation results after plastic film utilization suggest that decreasing plastic film residue after application is an effective measure to control PAE pollution in soils. However, the comparison between contamination levels of
\end{abstract}

\footnotetext{
Y. Chen · Q. Lin · Y. Hong

Key Laboratory of Urban Environment and Health, Institute of Urban Environment, Chinese Academy of Sciences, Xiamen, People's Republic of China

e-mail: yshchen421@163.com

C. $\mathrm{Wu}$

Nanjing University of Information Science and Technology,

Nanjing, People's Republic of China

H. Zhang · Y. Luo ( $\square)$

Yantai Institute of Coastal Zone Research, Chinese Academy

of Sciences, Yantai, People's Republic of China

e-mail: ymluo@yic.ac.cn
}

PAEs estimated by the model and the previous detections of PAEs pollution levels in agricultural soils showed that there were presented wide range of PAE sources indicated to agricultural soils.

Keywords Phthalate esters - Plastic film mulching · Pollution load · Contamination levels · Empirical estimation $\cdot$ Scenario

\section{Introduction}

Phthalate esters (phthalic acid esters, PAEs) are common plasticizers used to increase the flexibility, extensibility and ease of processing (workability) of polyvinyl chloride (PVC), with a constituent up to $50 \%$ of the total weight of PVC plastics (van Wezel et al. 2000). PAEs are not irreversibly bound to the polymer matrix, but present in the PVC as a freely mobile and leachable phase, resulting in migrating from the plastic to the external environment under certain conditions (Balafas et al. 1999; Gómez-Hens and Aguilar-Caballos 2003; Colombani et al. 2009). The yearly production of PVC is approximately 20 million tons, and it was estimated that the PVC waste amounts were up to 5.4 million tons in 2010 and a $40 \%$ rise of that waste is likely to occur in 2020 (Teil et al. 2006). Therefore, the environmental contamination levels will be enhanced because of the worldwide utilization of PAEs in plastic industry. At the present time, ubiquitous and serious contamination of PAEs in environmental matrices such as soil, water and air, has been reported in numerous studies (Mayer et al. 1972; Staples et al. 1997; Peijnenburg and Struijs 2006; Teil et al. 2006; Zeng et al. 2008).

After entering the environment, PAEs are redistributed among solid, aqueous and gas phases. Sorption, 
biodegradation, valorization and deposition may occur during PAEs' presentation processes. However, sustained release of PAEs from the plastic materials made the frequency detections of these compounds in environmental matrices. Some PAEs and their metabolites have been found to exhibit reproductive and developmental toxicities in laboratory animals and are regarded as a type of endocrine disruptor in environmental pollutants (Gray et al. 2000; Chen and Sung 2004; Matsumoto et al. 2008). Regulations have been made to control the widespread distribution of PAEs in the environment, especially of materials that have direct contacted with humans (Balafas et al. 1999; Amato et al. 2001). However, little consideration has been given to the plastic films used in agricultural production systems, despite the increasing use of these materials in crop cultivation.

In China, more than 1 million tons of plastic films are used each year in agricultural production to promote or protect crop growth (Department of rural social and economic investigation 2009). This indicates that relatively large amounts of plasticizers such as PAEs may be released into the environment from plastic films used for mulching (Gómez-Hens and Aguilar-Caballos 2003; Nørbygaard and Berg 2004; Navarro et al. 2010). Moreover, the plastic films used in agriculture are not recycled efficiently and some are allowed to remain in fields as fragments (up to $317.1 \mathrm{~kg} / \mathrm{ha} /$ year in Chinese vegetable fields). These residual mulching plastic films may persist in the field for long periods of time (up to 200-400 years) and continue to release PAEs into the soils (Wu 1994; Wang 1998; Xu et al. 2005).

Previous studies have shown that Chinese agricultural soils contain high levels of PAEs measured in magnitude of $\mathrm{mg} / \mathrm{kg}$ (Hu et al. 2003; Ma et al. 2003; Zeng et al. 2008; Chen et al. 2011). However, there have been few studies on the relationship between mulching with plastic film and PAE pollution levels in agricultural soils. The present study was therefore conducted to examine this relationship based on model calculation to estimate the pollution load and contamination levels of phthalate esters in soils on a national scale by empirical calculation. The calculations were based on the usage amounts of mulching plastic film and the residual rates of the films after their application. The aim was to identify effective control measure for PAE pollution by comparison between two plastic film management scenarios, recycling versus non-recycling.

\section{Materials and methods}

Model hypothesis

Phthalate esters released from plastic film into soils are affected by numerous factors such as the release rate from
PVC to soil, the degradation or dissipation rate in the soil and migration from soil to other environmental media. However, entrance and dissipation may occur simultaneously and their balance is determined by different factors such as climate, soil conditions and physicochemical properties of the compounds. It is difficult to develop algorithms to evaluate these environmental processes because of the lack of experimental data from laboratory and field. Thus, some hypothesis as below was assumed to fit the model calculation.

- No other sources of PAEs are present in the areas.

- Mulching plastic films lying on the soils are welldistributed.

- All PAEs will be rapidly released into soils from residual films.

- No degradation or dissipation of PAEs occurs in the soils.

- PAEs in soils do not transfer to surface waters, groundwater, air or elsewhere.

- PAEs released from residual films are well distributed in the topsoil (0-20 cm depth).

\section{Model description}

The utilization of plastic film mulching introduced the residual film pollution into soil environment, leading to the contamination of PAEs. Based on this principle, the residual film pollution is calculated by the amount of plastic film used and its residual rate, and the pollution load of the PAEs can be estimated by residual amount of plastic films and the proportion of PAEs in the films. Finally, pollution loads and contamination levels in the agricultural land mulched by plastic film can be calculated by the pollution load of the PAEs and soil area or soil weight. The model algorithms are detailed as follows:

$\mathrm{RFP}=F_{\mathrm{M}} \times F_{\mathrm{r}}$,

where RFP is the residual film pollution, measured in tons; $F_{\mathrm{M}}$ the amount of mulching plastic film used, measured in tons and $F_{\mathrm{r}}$ is the residual rate of mulching plastic film in the soils after its application, measured in \%, which is defined as percentage residual amount of the total amount of mulching plastic film used; the residual amount is calculated by the net increase between the total residual amount of plastic films in soils after crop harvest and the residual amount of plastic film before mulching.

$\mathrm{PAE}_{\text {total }}=\mathrm{RFP} \times P_{\mathrm{c}} \times \mathrm{PAE}_{\mathrm{c}}$,

where $\mathrm{PAE}_{\text {total }}$ is the total amount of PAEs released into agricultural land mulched by plastic film, measured in tons; $P_{\mathrm{c}}$ the content of plasticizers in PVC products by weight, 
measured in $\%$ and $\mathrm{PAE}_{\mathrm{c}}$ is the proportion of PAEs used as plasticizers in plastic film production, measured in $\%$.

$P A E_{\text {load }}=\frac{P A E_{\text {total }}}{\mathrm{A}}$,

where $\mathrm{PAE}_{\text {load }}$ is the pollution load of PAEs in agricultural land mulched by plastic film, measured in $\mathrm{kg} / \mathrm{ha} /$ year and $A$ is the area of agricultural land mulched with plastic film, measured in ha.

$\mathrm{PAE}_{\text {soil }}=\frac{\mathrm{PAE}_{\text {total }} \times 10^{9}}{\mathrm{SW}}$

$\mathrm{SW}=A \times D \times \rho$,

where $\mathrm{PAE}_{\text {soil }}$ is the contamination levels of PAEs in topsoil in the agricultural land mulched with plastic film, measured in $\mathrm{mg} / \mathrm{kg} ; 10^{9}$ the unit conversion factor between $\mathrm{t}$ and $\mathrm{mg}$; SW the weight of topsoil in the agricultural land mulched with plastic film, measured in $\mathrm{kg} ; A$ the area of agricultural land mulched with plastic film, measured in $\mathrm{m}^{2} ; D$ the depth of agricultural land in which PAEs are present, measured in $\mathrm{m}$ and $\rho$ is the bulk density of the soil, measured in $\mathrm{kg} / \mathrm{m}^{3}$.

\section{Determination of model parameters}

According to the parameter descriptions, $F_{\mathrm{M}}$ and $A$ can be obtained directly from the statistical yearbook. The others are available from references and used for calculation. The processes used for determining parameter values are described below.

$F_{\mathrm{M}}$ and $A$ were obtained from the Chinese Rural Statistical Yearbook 2009 (Department of rural social and economic investigation 2009), and the data were recorded separately for different provinces or cities (Table 1; Fig. 1).

It is difficult to obtain an accurate residual rate of mulching plastic film for each province or city as it is affected by many factors such as cropping system, climate, cultivation practices, soil type and plastic film type. In different regions, $F_{\mathrm{r}}$ was a variable and the detailed values in estimation were determined according to the China Pollution Source Census (discussed in the results).

The amount of plasticizer in PVC formulations depends on the required properties and can vary from 15 to $60 \mathrm{wt} \%$ as a function of the final application. In general, formulations with around 35-40\% plasticizer are the most common in PVC production (Gómez-Hens and Aguilar-Caballos 2003; Nørbygaard and Berg 2004; Navarro et al. 2010). In the present study, $P_{\mathrm{c}}$ was assumed to be $35 \%$ for the model.

There are no data available on the amounts of PAEs used as plasticizers during plastic film production in China. It has been reported that $88 \%$ plasticizer in consumption is
PAEs worldwide and about $70 \%$ in the USA (Tao and Liang 2008; Stuart et al. 2010). The value of $70 \%$ for PAEc was therefore used for calculation for conservation in the present study.

$D$ is the depth of topsoil in which the PAEs are present. $D$ was taken as $0.2 \mathrm{~m}$ for calculation.

The value of $\rho$ can also vary among different agricultural regions but for ease of comparison $1,500 \mathrm{~kg} / \mathrm{m}^{3}$ was used in the present study.

\section{Results}

Determining the $F_{\mathrm{r}}$ in agricultural land in China

Most plastic film enters the soils after mulching because it is difficult and time consuming to recycle, resulting in a large amount of plastic film pollution on agricultural land that has been mulched with plastic film (Wu 1994; Wang 1998). According to China Pollution Source Census, the Chinese agricultural lands mulched by plastic films can be divided into six growing regions with two management scenarios (recycling and non-recycling). The residue rates from different fields in these regions were calculated by fixed position investigations (total 432 positions in whole countries) conducted over 1 year, based on the examination of 5 pits (each $2 \mathrm{~m}^{2}$ in area and $20 \mathrm{~cm}$ deep) in each mulching area with an area of about $667 \mathrm{~m}^{2}$ (the selected pits were positioned in a quincunx geometric pattern in each survey area). The results showed that recycling management (recycling or non-recycling) was the most important factor affecting plastic film pollution in mulching areas (Table 1; Fig. 1). It is difficult in practice to recycle plastic film after it has been used in the field, especially in large productions areas such as cotton fields because the film is thin, flexible and readily broken up into small fragments during cultivation. As a result, ubiquitous plastic film pollution has been occurring in these agricultural lands mulched with plastic film (Du et al. 2005; Ma et al. 2008). In addition, the climate and topography of different regions also affect the residue rates to a great extent, leading to high variation in pollution under the same film management practice (Table 1).

\section{Pollution load of PAEs across China}

The amounts of PAEs released based on plastic film pollution were expected to be dependent on the amount of mulching plastic film used and residual rates from different provinces or cities. Figure 2 presents the pollution load of PAEs released from plastic film across China. Under the nonrecycling scenario, five areas (Beijing City, Tibet, Liaoning Province, Jilin Province and Fujian Province) released PAEs 
Table 1 Data information for model calculation

\begin{tabular}{|c|c|c|c|c|c|}
\hline Region & Provinces or cities & $\begin{array}{l}\text { Total plastic } \\
\text { film load }(\mathrm{t} / \\
\text { year) }\end{array}$ & $\begin{array}{l}\text { Residual rates }(\%)^{\mathrm{a}} \text { in } \\
\text { non-recycling scenario }\end{array}$ & $\begin{array}{l}\text { Residual rates }(\%)^{\mathrm{a}} \text { in } \\
\text { recycling scenario }\end{array}$ & $\begin{array}{l}\text { Plastic film } \\
\text { mulched land area } \\
\text { (ha) }\end{array}$ \\
\hline \multirow[t]{5}{*}{$\begin{array}{l}\text { Plateaux and mountain } \\
\text { areas of north China }\end{array}$} & $\begin{array}{l}\text { Inner Mongolia } \\
\text { Autonomous } \\
\text { Region }\end{array}$ & $39,070.0$ & 29.7 & 4.9 & 736,174 \\
\hline & Shaanxi Province & $18,981.0$ & 29.7 & 4.9 & 439,338 \\
\hline & Gansu Province & $54,690.0$ & 29.7 & 4.9 & 784,053 \\
\hline & $\begin{array}{l}\text { Ningxia Hui } \\
\text { Autonomous } \\
\text { Region }\end{array}$ & $4,778.0$ & 29.7 & 4.9 & 115,039 \\
\hline & Shanxi Province & $24,916.0$ & 29.7 & 4.9 & 456,142 \\
\hline \multirow[t]{3}{*}{$\begin{array}{l}\text { Semi-humid plains of } \\
\text { northeast China }\end{array}$} & $\begin{array}{l}\text { Heilongjiang } \\
\text { Province }\end{array}$ & $26,732.0$ & 44.9 & 6.6 & 327,560 \\
\hline & Liaoning Province & $31,656.0$ & 44.9 & 6.6 & 249,428 \\
\hline & Jilin Province & $17,970.5$ & 44.9 & 6.6 & 149,116 \\
\hline \multirow{7}{*}{$\begin{array}{l}\text { Semi-humid plains of } \\
\text { Yellow, Huai and Hai } \\
\text { Rivers }\end{array}$} & Beijing City & $5,038.0$ & 35.6 & 15.7 & 22,162 \\
\hline & Tianjing City & $6,458.0$ & 35.6 & 15.7 & 100,505 \\
\hline & Hebei Province & $63,424.0$ & 35.6 & 15.7 & $1,097,496$ \\
\hline & Shandong Province & $148,190.0$ & 35.6 & 15.7 & $2,607,608$ \\
\hline & Henan Province & $61,525.0$ & 35.6 & 15.7 & 960,380 \\
\hline & Anhui Province & $35,030.0$ & 35.6 & 15.7 & 502,927 \\
\hline & Jiangsu Province & $35,308.0$ & 35.6 & 15.7 & 493,807 \\
\hline \multirow{9}{*}{$\begin{array}{l}\text { Mountain and hilly areas of } \\
\text { south China }\end{array}$} & Zhejiang Province & $24,096.0$ & 18.1 & 8.5 & 148,070 \\
\hline & Fujian Province & $35,802.0$ & 18.1 & 8.5 & 122,095 \\
\hline & $\begin{array}{l}\text { Guangdong } \\
\text { Province }\end{array}$ & $19,569.0$ & 18.1 & 8.5 & 113,174 \\
\hline & $\begin{array}{l}\text { Guangxi Zhuang } \\
\text { Autonomous } \\
\text { Region }\end{array}$ & $21,632.0$ & 18.1 & 8.5 & 305,508 \\
\hline & Hainan Province & $6,815.0$ & 18.1 & 8.5 & 33,893 \\
\hline & Guizhou Province & $19,838.0$ & 18.1 & 8.5 & 226,611 \\
\hline & Yunnan Province & $58,272.0$ & 18.1 & 8.5 & 724,828 \\
\hline & Shanghai City & $7,121.0$ & 18.1 & 8.5 & 32,592 \\
\hline & Jiangxi Province & $24,916.0$ & 18.1 & 8.5 & 134,631 \\
\hline \multirow{4}{*}{$\begin{array}{l}\text { Humid plains of south } \\
\text { China }\end{array}$} & Chongqing City & $18,257.0$ & 35.4 & 9.3 & 341,118 \\
\hline & Sichuan Province & $71,026.0$ & 35.4 & 9.3 & 832,042 \\
\hline & Hubei Province & $33,002.0$ & 35.4 & 9.3 & 516,890 \\
\hline & Hunan Province & $49,328.0$ & 35.4 & 9.3 & 687,498 \\
\hline \multirow{3}{*}{$\begin{array}{l}\text { Arid and semi-arid plains of } \\
\text { northwest China }\end{array}$} & Tibet & 389.0 & 52.7 & 16.2 & 2,865 \\
\hline & Qinghai & 515.0 & 52.7 & 16.2 & 6,865 \\
\hline & $\begin{array}{l}\text { Xinjiang Uygur } \\
\text { Autonomous } \\
\text { Region }\end{array}$ & $149,114.0$ & 52.7 & 16.2 & $2,037,660$ \\
\hline
\end{tabular}

$\overline{{ }^{a}}$ Residual rate $=$ (total residual amount of plastic film in soil after harvest - residual amount of plastic film before mulching)/total amount of mulching plastic film used

into the soils after plastic film mulching, with pollution loads of $19.8,17.5,14.0,13.3$ and $13.0 \mathrm{~kg} / \mathrm{ha} /$ year PAEs, respectively. This is in relation to the intensity of agricultural mulching activity in these provinces, suggesting that higher pollution load of PAEs occur in the provinces that are well known for their use of mulching in agricultural production.
The highest pollution load occurred in Beijing City where very large amounts of plastic film were used for vegetable production to maintain optimum growth conditions. However, under the recycling scenario, only Beijing City, Tibet and Fujian Province reached amounts of more than $5 \mathrm{~kg} / \mathrm{ha} /$ year of PAEs load. Tibet, which contains fewer greenhouses 
Fig. 1 The sub-regions of different $F_{\mathrm{r}}$ value in the agricultural soils in China

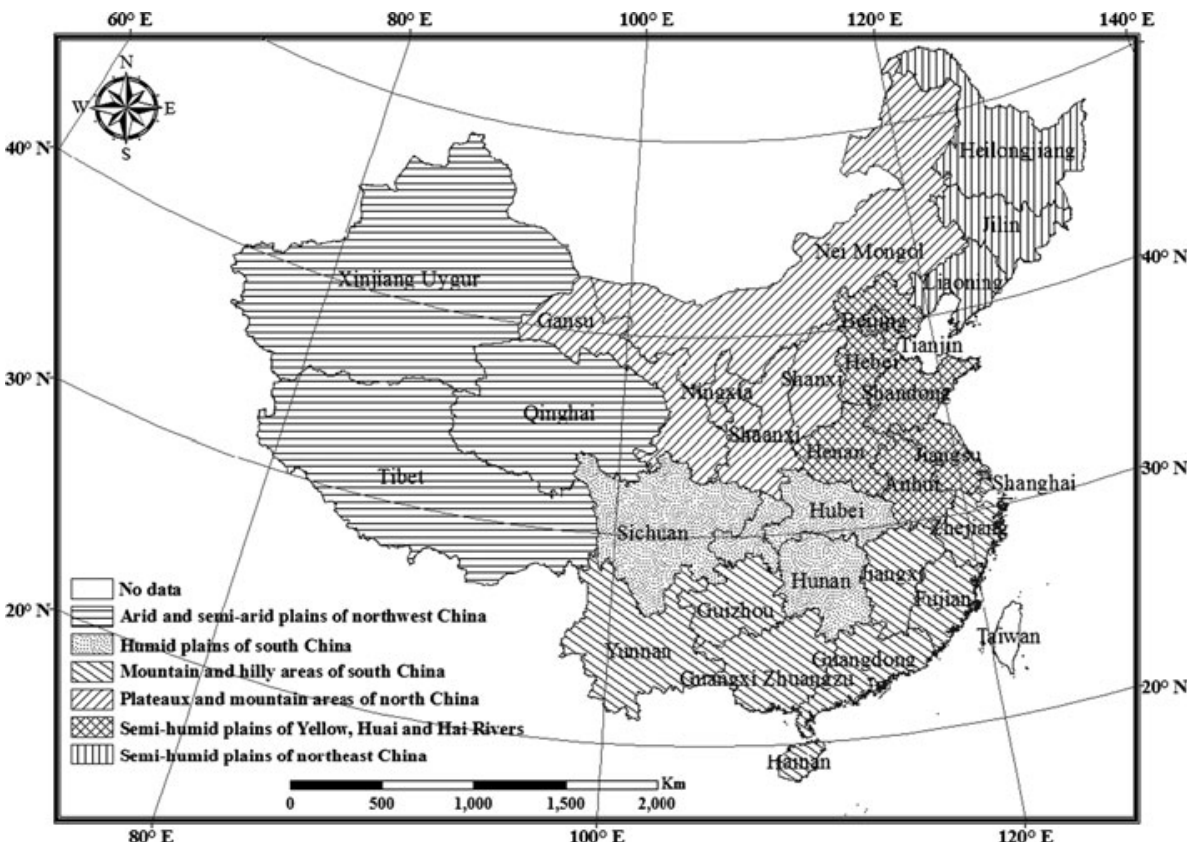

with plastic film because of their climate and landscape features, 50.2 tons of PAEs are released with non-recycling and 15.4 tons are released without recycling, respectively. However, high residual rate of mulching plastic film of Tibet led to high pollution load of PAEs in its mulching lands, because of the difficulty in collecting the PVC fragments in this cold and high latitude place. Xinjiang Uygur Autonomous Region and Shandong Province released the highest PAEs after plastic film mulching (more than 10,000 tons in non-recycling scenario and more than 5,000 tons in recycling scenario), but only presented 9.4 and $2.9 \mathrm{~kg} / \mathrm{ha} /$ year of PAEs load in soils for Xinjiang as well as 5.0 and $2.2 \mathrm{~kg} / \mathrm{ha} /$ year for Shandong in non-recycling scenario and in recycling scenario, respectively. Large land area could be the main reason for these differences. Since the plastic film pollution is common in Chinese agricultural fields, with contamination levels ranging from 60 to $90 \mathrm{~kg} / \mathrm{ha}$ (Yan et al. 2006), agricultural soil polluted by PAEs load is therefore ubiquitous.

\section{Contamination levels of PAEs in Chinese soils}

All the PAEs released from mulching plastic film can be expected to enter the soils if it is assumed that there is no degradation or transfer during release. Thus, the contamination levels of PAEs in soils in different provinces (or cities) has been estimated based on the pollution loads presented in Fig. 2. As with the pollution load estimation, estimates of PAE contamination levels also depend on film management (recycling or non-recycling) after mulching (Fig. 3). With recycling, Fujian Province and Beijing City were contaminated badly by PAEs, with the pollution levels of 2.1 and $2.9 \mathrm{mg} / \mathrm{kg}$, respectively. However, without recycling, contamination levels of PAEs in soils of 14 provinces (or cities) in 31 areas studied were estimated to be greater than $2.0 \mathrm{mg} / \mathrm{kg}$, reaching 5.8 and $6.6 \mathrm{mg} / \mathrm{kg}$, respectively, for Tibet and Beijing City. In addition, the contamination levels (Fig. 3) in the mulching fields from 31 provinces (or cities) were estimated to be more than $1.0 \mathrm{mg} / \mathrm{kg}$ under non-recycling compared with those exceeding $1.0 \mathrm{mg} / \mathrm{kg}$ with recycling from only 8 areas (Zhejiang, Guangdong, Jiangxi, Hainan, Shanghai, Tibet, Fujian and Beijing). Therefore, plastic film management was effective to control PAE contamination in soils. Unfortunately, little attention is paid to this effective control measure, leading to high PAE contamination levels in most Chinese agricultural soils (Hu et al. 2003; Ma et al. 2003; Zeng et al. 2008). The predicted concentrations of PAEs in soils exceed the target value for soils from Netherlands ( $\Sigma$ PAEs $=0.1 \mathrm{mg} / \mathrm{kg}$; Carlon 2007), indicating very high contamination of most Chinese agricultural soils with plastic film residues. In addition, many sources of PAEs other than plastic film such as sewage sludge application, disposal of other plastic products and atmospheric deposition can also introduce PAEs into soils (Bauer and Herrmann 1997; Cai et al. 2007; Zeng et al. 2010), resulting in more serious situation of PAEs contamination in Chinese agricultural soils.

\section{Discussion}

Mulching plastic film residues produce negative impacts on soil physical properties and crop growth and also introduce harmful pollutants into soils that may impact on ecosystem 

released from mulching plastic film residues in agricultural land in China
Fig. 2 Pollution load of PAEs
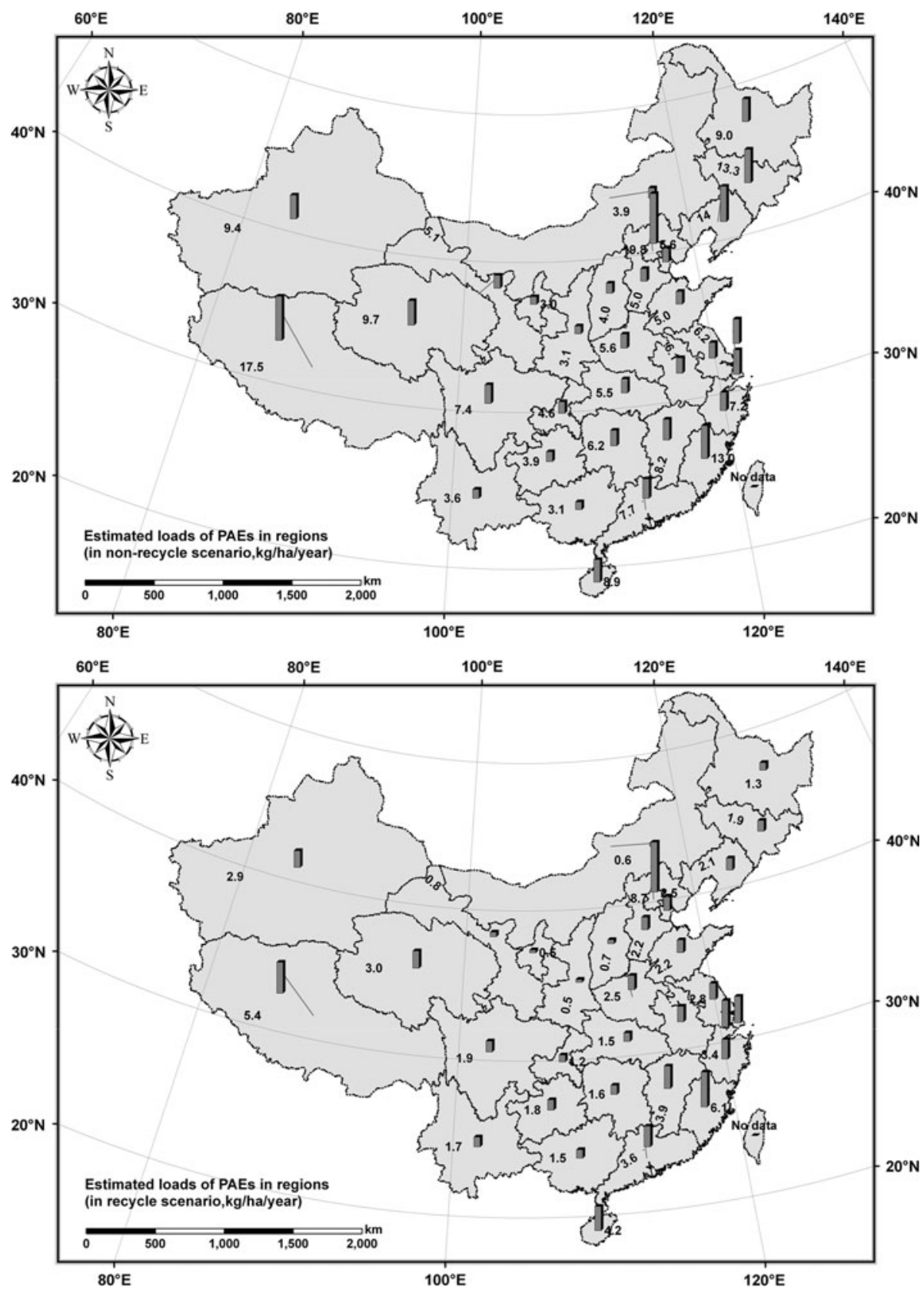

or human health. PAEs are important contaminants derived from mulching plastic film residues because of their common and large-scale use as plasticizers in PVC film. Moreover, freely mobile and leachable phase PAEs in PVC products enhance PAE release from the residues of plastic films (Amato et al. 2001; Gómez-Hens and AguilarCaballos 2003; Colombani et al. 2009). As a result, ubiquitous PAE pollution occurs in agricultural land mulched with plastic film (Ma et al. 2003; Chen et al. 2011). Very large amounts of plastic film were used to improve cultivation conditions in China, leading to high contamination levels of mulching plastic film residues in agricultural fields (Wu 1994; Wang 1998; Xu et al. 2005; Yan et al. 2006).
Therefore, high concentrations of PAEs in soils were assumed to originate from applications of larger amounts of plastic film (Hu et al. 2003). In parallel with this situation, the pollution load and contamination levels of PAEs in soils, estimated by the model, were attributable to the amount of plastic film used and the residue rate of plastic film following its utilization.

Those areas where larger amounts of plastic film are used will have higher residues, resulting in higher pollution load and higher PAE contamination levels in the soil. However, pollution load and levels are largely controlled by film management scenario after application (recycling versus non-recycling). Much lower pollution load and 
Fig. 3 Contamination levels of PAEs released from mulching plastic film residues in agricultural soils in China
Fig. 4 Comparison between contamination levels of PAEs estimated by the model and the previous detection of PAE pollution levels in agricultural soils. Notes the published data were obtained from the references by Ma et al. 2003; $\mathrm{Hu}$ et al. 2003; Guan et al. 2007 and Zeng et al. 2008. The error bars of $\mathrm{Y}$ value were calculated from these published data detected in the same provinces or cities
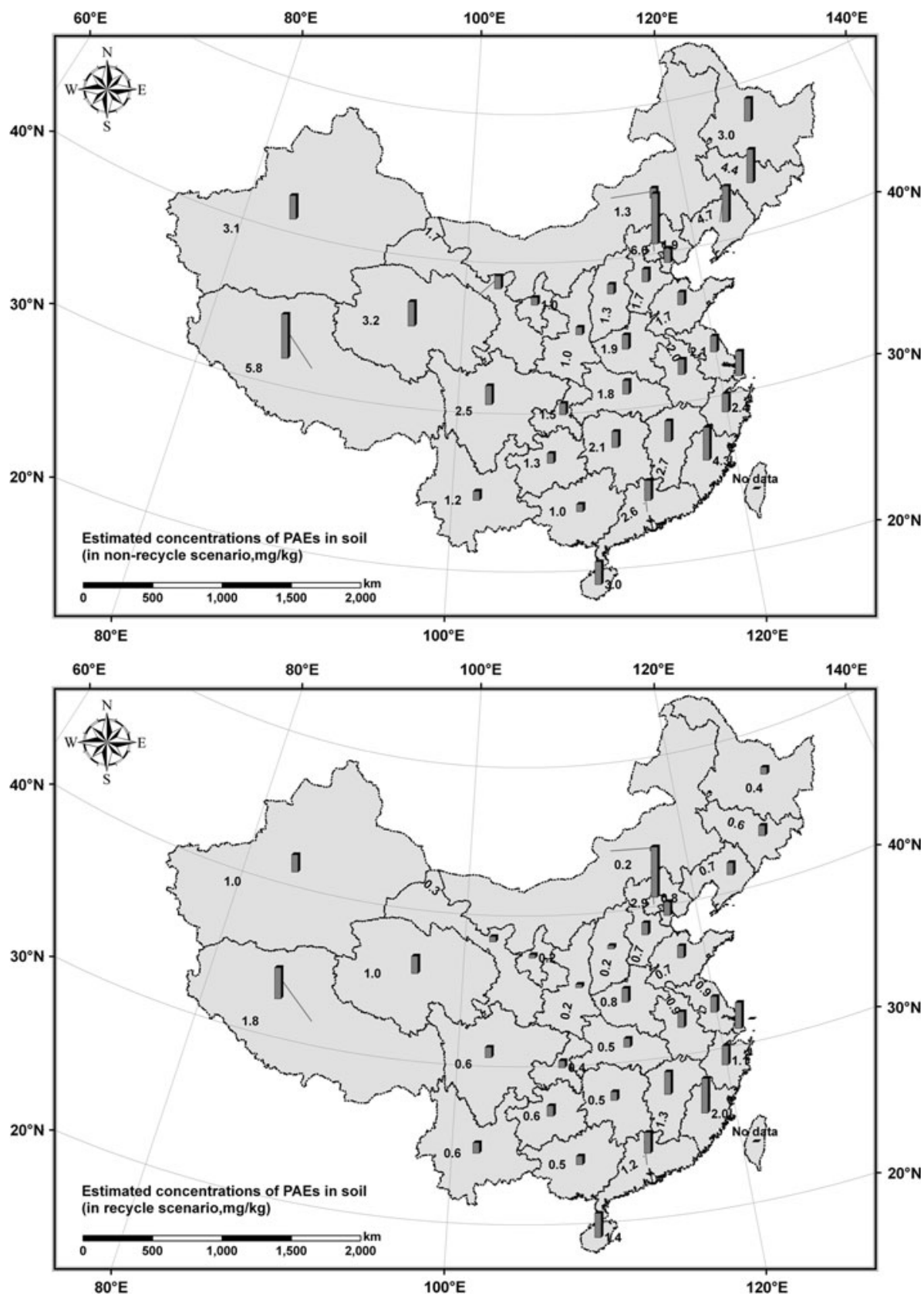

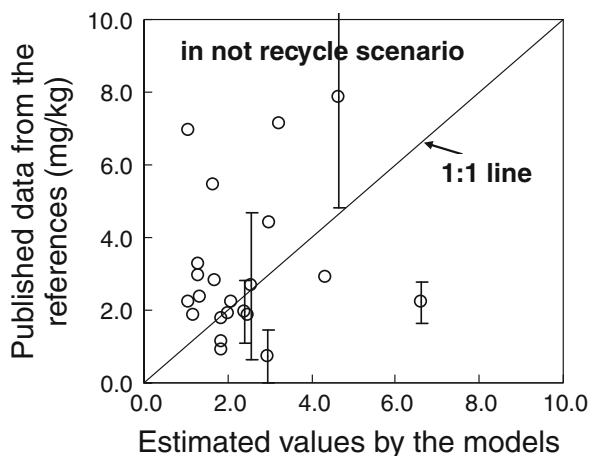

$(\mathrm{mg} / \mathrm{kg})$

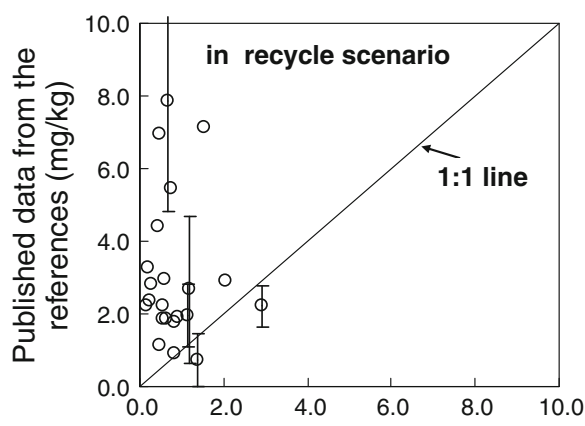

Estimated values by the models $(\mathrm{mg} / \mathrm{kg})$ 
contamination levels occurred under recycling management, indicating that recycling is an effective way to control PAE pollution in agricultural soils. However, soil pollution by PAEs can occur from numerous anthropogenic sources such as sewage sludge application, irrigation with polluted water and disposal of other plastic products (Bauer and Herrmann 1997; Cai et al. 2007; Wang et al. 2008). In addition, atmospheric deposition and fertilizer application can also introduce PAEs into the soil (Mo et al. 2008; Zeng et al. 2010). As a result, the contamination levels of PAEs estimated by the model were lower than previously determined values in Chinese agricultural soils, especially under recycling management (Fig. 4). Moreover, the contamination levels from mulching plastic film under field conditions will be much lower than the predicted values because PAE release from mulching plastic film is a slow process, and degradation and migration usually occur during the release process (Zheng et al. 2007; Xu et al. 2008). It is therefore important to ensure that all sources of PAE pollution in agricultural soils should be identified and quantified in future studies to improve model predictions.

\section{Summary and conclusions}

The current study presented a simple model to calculate the pollution load and contamination levels of PAEs in agricultural land from plastic film mulching. The results indicate that the pollution loads and contamination levels of soils in different provinces (or cities) were dependent on the amount of plastic film used and its residue rate in the field. However, whether the film is recycled or not recycled can dramatically affect the estimates, resulting in much lower pollution loads or contamination levels with recycling management. When recycling is not practised, pollution loads with more than $10 \mathrm{~kg} / \mathrm{ha} /$ year of PAEs can be presented in the soils of Beijing City, Tibet, Liaoning Province, Jilin Province and Fujian Province. However, with recycling, only Beijing City, Tibet and Fujian Province reached amounts of more than $5 \mathrm{~kg} / \mathrm{ha} /$ year of PAEs load. Under the non-recycling scenario, contamination levels of PAEs in soils of 14 provinces (or cities) in 31 areas studied were estimated to be greater than $2.0 \mathrm{mg} / \mathrm{kg}$, reaching 5.8 and $6.6 \mathrm{mg} / \mathrm{kg}$, respectively, in Tibet and Beijing City. Under the recycling scenario only Fujian Province and Beijing City were estimated to be greater than $2.0 \mathrm{mg} / \mathrm{kg}$. Comparing with the target value for soils of Netherlands ( $\Sigma$ PAEs $=0.1 \mathrm{mg} / \mathrm{kg}$ ), all the agricultural soils from the studied areas presented high environmental risk to soil ecosystems. Moreover, the contamination levels of PAEs estimated by the model were lower than previous levels detected in Chinese agricultural soils, especially with recycling of plastic film, indicating serious situation of PAEs contamination in Chinese agricultural soils.
Acknowledgments We thank Peter Christie, from Department of Agriculture and Rural Development for Northern Ireland, AgriEnvironment Branch, Agri-Food and Biosciences Institute, for his kind help in language polishing. This research was funded by National Natural Science Foundation of China (No. 41006064); the Special Environmental Protection Fund for Public Welfare Industry (No.201109018-4), Fujian Provincial Natural Science Foundation of China (No. 2012J05081) and Water Special Project (2008ZX07101006-05)

\section{References}

Amato B, Karl S, Ng C (2010) Phthalate plasticizer (CE 435 April 6, 2001), Available on line: http://www.eng.buffalo.edu/Courses/ ce435/2001ZGu/Phthalate_Plasticizers/PhthalatePlasticizersReport. htm. Accessed 28 Oct. 2010

Balafas D, Shaw KJ, Whitfield FB (1999) Phthalate and adipate esters in Australian packaging materials. Food Chem 65:279-287

Bauer MJ, Herrmann R (1997) Estimation of the environmental contamination by phthalic acid esters leaching from household wastes. Sci Total Environ 208:49-57

Cai QY, Mo CH, Wu QT, Zeng QY, Katsoyiannis A (2007) Occurrence of organic contaminants in sewage sludges from 11 wastewater treatment plants, China. Chemosphere 68:1751-1762

Carlon C (2007) Derivation methods of soil screening values in Europe. A review and evaluation of national procedures towards harmonisation-a report of the ENSURE Action. 2007, ANNEX3: Screening Value. Available on line: http://eusoils.jrc. it/ESDB_Archive/eusoils_docs/other/EUR22805.pdf

Chen WL, Sung HH (2004) The toxic effect of phthalate esters on immune responses of giant freshwater Prawn (Macrobrachiun rosenbergii) via oral treatment. Aquat Toxicol 74:160-171

Chen YS, Luo YM, Zhang HB, Song J (2011) Preliminary study on PAEs pollution of greenhouse soils. Acta Pedol Sin 48(3):518-523 (in Chinese with English abstract)

Colombani J, Herbette G, Rossi C, Joussot-Dubien C, Labed V, Gilardi T (2009) Leaching of plasticized PVC: effect of irradiation. J Appl Polym Sci 112:1372-1377

Department of Rural Social and Economic Investigation (2009) National Bureau of Statistics of China. Chinese rural statistical yearbook 2009, P44

Du XM, Xu G, Xu DP, Zhao TK, Li FS (2005) Mulch film residue contamination in typical areas of North China and countermeasures. Trans Chin Soc Agric Eng 21:225-227 (in Chinese with English abstract)

Gómez-Hens A, Aguilar-Caballos MP (2003) Social and economic interest in the control of phthalic acid esters. TrAC Trends Anal Chem 22:847-857

Gray LE, Ostby J, Furr J, Price M, Rao Veeramachaneni DN, Parks L (2000) Perinatal exposure to the phthalates DEHP, BBP and DINP, but not DEP, DMP or DOTP, alters sexual differentiation of the male rat. Toxicol Sci 58:350-365

Guan H, Wang JS, Wan HF, Li PX, Yang GY (2007) PAEs pollution in soil from typical agriculture area of Leizhou peninsula. J AgoEnviron Sci 26(2):622-628 (in Chinese with English abstract)

Hu XY, Wen B, Shan XQ (2003) Survey of phthalate pollution in arable soils in China. J Environ Monit 5:649-653

Ma LL, Chu SG, Xu XB (2003) Organic contamination in the greenhouse soils from Beijing suburbs, China. J Environ Monit 5:786-790

Ma H, Mei XR, Yan SR, He WQ, Li K (2008) The residue of mulching plastic film of cotton field in North China. J AgroEnviron Sci 27(2):570-573 (in Chinese with English abstract) 
Matsumoto M, Hirata-Koizumi M, Ema M (2008) Potential adverse effects of phthalic acid esters on human health: a review of recent studies on reproduction. Regul Toxicol Pharm 50:37-49

Mayer FL, Stalling DL, Johnson JL (1972) Phthalate esters as environmental contaminants. Nature 238:411-413

Mo CH, Cai QY, Li YH, Zeng QY (2008) Occurrence of priority organic pollutants in the fertilizers, China. J Hazard Mater 152:1208-1213

Navarro R, Perrino MP, Tardajos MG, Reinecke H (2010) Phthalate plasticizers covalently bound to PVC: plasticization with suppressed migration. Macromolecules 43:2377-2381

Nørbygaard T, Berg RW (2004) Analysis of phthalate ester content in poly (vinyl chloride) plastics by means of fourier transform raman spectroscopy. Appl Spectrosc 58:410-413

Peijnenburg WJ, Struijs J (2006) Occurrence of phthalate esters in the environment of The Netherlands. Ecotox Environ Safe 63:204-215

Staples CA, Peterson DR, Parkerton TF, Adams WJ (1997) The environmental fate of phthalate esters: a literature review. Chemosphere 35:667-749

Stuart A, McCallum MM, Fan D, LeCaptain DJ, Lee CY, Mohanty DK (2010) Poly(vinyl chloride) plasticized with succinate esters: synthesis and characterization. Polym Bull 65:589-598

Tao G, Liang C (2008) Analysis on the development tendency of domestic and global market. Plast Technol 36(6):78-81 (in Chinese with English abstract)

Teil MJ, Blanchard M, Chevreuil M (2006) Atmospheric fate of phthalate esters in an urban area (Paris, France). Sci Total Environ 354:212-223

van Wezel AP, van Vlaardingen P, Posthumus R, Crommentuijn GH, Sijm DTHM (2000) Environmental risk limits for two phthalates, with special emphasis on endocrine disruptive properties. Ecotoxicol Environ Saf 46:305-321
Wang P (1998) Measures to reduce the pollution of residual of mulching plastic film in farmland. Trans Chin Soc Agric Eng 14(3):185-188 (in Chinese with English abstract)

Wang F, Xia XH, Sha YJ (2008) Distribution of phthalic acid esters in wuhan section of the Yangtze River, China. J Hazard Mater 154:317-324

Wu JM (1994) Persistence and biodegradation of polyolefin plastic films and phthalate esters in the environment. Chin J EnvironSci 15(2):77-80 (in Chinese with English abstract)

Xu G, Du XM, Cao YZ, Wang QH, Xu DP, Lu GL, Li FS (2005) Residue levels and morphology of agricultural plastic film in representative areas of China. J Agro-Environ Sci 24(1):79-83 (in Chinese with English abstract)

$\mathrm{Xu}$ G, Li FS, Wang QH (2008) Occurrence and degradation characteristics of dibutyl phthalate (DBP) and di-(2-ethylhexyl) phthalate (DEHP) in typical agricultural soils of China. Sci Total Environ 393:333-340

Yan CR, Mei XR, He WQ, Zheng SH (2006) Present situation of residue pollution of mulching plastic film and controlling measures. Trans Chin Soc Agric Eng 22(11):269-272 (in Chinese with English abstract)

Zeng F, Cui K, Xie Z, Wu L, Liu M, Sun G, Lin Y, Luo D, Zeng Z (2008) Phthalate esters (PAEs): emerging organic contaminants in agricultural soils in peri-urban areas around Guangzhou, China. Environ Pollut 56:425-434

Zeng F, Lin YJ, Cui KY, Wen JX, Ma YQ, Chen HL, Zhu F, Ma ZL, Zeng ZX (2010) Atmospheric deposition of phthalate esters in a subtropical city. Atmos Environ 44:834-840

Zheng Z, He PJ, Shao LM, Lee DJ (2007) Phthalic acid esters in dissolved fractions of landfill leachates. Water Res 41: 4696-4702 